\title{
CONTRATUALISMO E BIOPODER
}

\author{
CONTRATUALISM AND BIOPOWER
}

\section{Maria Elizabeth Bueno de Godoy ${ }^{1}$ Luiz Maurício Bentim da Rocha Menezes ${ }^{2}$}

\begin{abstract}
Resumo: A teoria do contrato social teve forte recepção no pensamento filosófico moderno e podemos atribuir à filosofia política de Thomas Hobbes o amadurecimento e disseminação dessa teoria, de grande contribuição para o pensamento político posterior. Partindo de um problema do direito natural, Hobbes irá identificar a vontade ilimitada de poder nas paixões humanas e a disputa constante entre os homens no estado de natureza. Será partindo dessa observação que ele verá a necessidade de um poder superior que regule essas paixões. O Estado é fruto desse poder, que terá sua gênese na paixão do medo da morte violenta, existente em todos os homens. Visto isso, será o medo que levará os homens a cederem seus poderes (direito a todas as coisas) através de um contrato que irá permitir a formação desse poder maior que é o corpo político (Estado). Dessa forma, o Estado adquire a soberania e o poder soberano sobre os corpos naturais dos homens, tendo, portanto, o poder sobre a vida deles. Será o poder da soberania, oriundo do referido contrato e da sujeição dos homens a esse poder, que Foucault irá criticar através de seu conceito de biopoder.
\end{abstract}

Palavras-Chave: Hobbes. Foucault. Biopoder. Biopolítica. Contratualismo.

\begin{abstract}
The social contract theory had a wide reception in the modern philosophical thought, and one might address to Thomas Hobbes' philosophy of politics the matureness and dissemination of this very theory, of great contribution to the later political thought. Starting from a question on natural right Hobbes will identify the unlimited will of power which relies on human passions, and the everlasting dispute amongst men in state of nature. It is from this observation that he will acknowledge the need of a superior power regulating these passions. The State is the result of this very power, which finds its origin in the passion of fear of a violent death, common to every men. Therefore, it will be fear, taking men to hand in their powers (the right to everything whatsoever), by means of a contract, which allows the formation of this greater power, or, the body politic (State). Thus, the State acquires sovereignty and sovereign power over the natural bodies of men, thusly, the power over their very lives. It will be this sovereignty power, product of the referred contract and of subjection of men to the former, that Foucault will criticise through his biopower concept.
\end{abstract}

Keywords: Hobbes. Foucault. Biopower. Biopolitics. Contractualism.

\section{INTRODUÇÃO}

A teoria do contrato social teve forte recepção no pensamento filosófico moderno. Podemos atribuir à filosofia política de Thomas Hobbes o amadurecimento e disseminação dessa

${ }^{1}$ Doutora em História Social pela Faculdade de Filosofia, Letras e Ciências Humanas da USP. Professora de Filosofia Antiga e Medieval do Colegiado de Filosofia da Universidade do Estado do Amapá (UEAP). Lattes: http://lattes.cnpq.br/4756557048763454. Orcid: http://orcid.org/0000-0002-7070-2994

2 Doutor em Filosofia pelo PPGLM/UFRJ. Professor de Filosofia, Ética e Política do Instituto Federal do Triângulo Mineiro (IFTM). Lattes: http://lattes.cnpq.br/5932586465926963. Orcid: http://orcid.org/0000-0003-4925-9876 
teoria, trazendo grande contribuição para o pensamento político posterior. No entanto, o contratualismo não é uma teoria fundada na modernidade; tem bases profundas na antiguidade clássica, identificando-se um primeiro tatear entre os sofistas gregos do século $\mathrm{V}$ a.C. De acordo com Guthrie:

Com a mudança que ocorreu no séc. V, mergulhamos numa discussão de problemas que são tão relevantes hoje como o foram quando levantados pela primeira vez pelos sofistas. O que quer que pensemos do movimento sofista, devemos todos estar de acordo que nenhum movimento intelectual pode-se comparar com ele na permanência de seus resultados, e que as questões propostas pelos sofistas nunca se permitiram repousar na história do pensamento ocidental até os nossos dias (GUTHRIE, 2007, p. 9).

Se podemos dizer que os problemas levantados no séc. V a.C. repercutem até hoje no desenvolvimento das ideias ocidentais, é mais do que relevante retomarmos a discussão sobre o contratualismo. No mais, é importante ressaltarmos a importância dos estudos teóricos dentro do âmbito acadêmico, tanto para o desenvolvimento de hipóteses filosóficas como para o debate na história das ideias. O século $\mathrm{V}$ a. C. é o século em que se começa a desenvolver as primeiras teorias contratualistas colocando em oposição a lei (nómos) e a natureza (phýsis). Já "em princípios do século XVII, o conceito de Estado - sua natureza, seus poderes, seu direito de exigir obediência - passara a ser considerado o mais importante objeto de análise no pensamento político europeu" (SKINNER, 1996, p. 617). Se somarmos isso ao pensamento hobbesiano do contrato, veremos de que maneira se constituiu o Estado moderno.

$\mathrm{Na}$ primeira parte de nosso trabalho, iremos nos centrar na base do contrato proposto por Hobbes, o que implica em, primeiramente, entender o que o autor quer dizer com natureza humana e quais as consequências da convivência fora da soberania do Estado em suas vidas. Desse modo, é preciso observar em que consiste o direito natural e de que maneira poderíamos decorrer o corpo político das leis naturais, o que levaria à análise do poder soberano na vida em sociedade e qual a sua função para o desenvolvimento pleno de Estado, tomando como obra principal o Leviathan.

$\mathrm{Na}$ segunda parte, iremos verificar a crítica de Michel Foucault ao poder exercido pelo Estado e aos modos pelos quais o poder pode ser exercido. Dessa forma, pretende-se estudar os conceitos de biopoder e biopolítica cunhados por Foucault e quais as suas implicações para a sociedade hodierna.

\section{HOBBES E O PODER SOBERANO}

Hobbes no Leviathan faz, na primeira parte da obra, uma análise do que constitui o homem. Somente a partir do conceito de natureza humana e de corpo natural é que ele poderá desenvolver a sua teoria do corpo político e a gênese do Estado. Hobbes apresenta o estado de natureza humano no capítulo XIII. Segundo ele, o homem é igual por natureza tanto nas faculdades do corpo como na do espírito ${ }^{3}$. Se todos os homens possuem força e inteligência semelhantes, então estão na mesma condição natural. Essa igualdade natural não nos traz nenhuma segurança, pois se na natureza não há qualquer tipo de poder capaz de coagi-los a agir

${ }^{3}$ HOBBES, T. Leviatã. Tradução de João Paulo Monteiro e Maria Beatriz Nizza da Silva. São Paulo Martins Fontes, 2008, p. 106. Demais citações à obra serão abreviadas por Lev. seguidas da página.

PRACS: Revista Eletrônica de Humanidades do Curso de Ciências Sociais da UNIFAP 
segundo regras e, dessa forma, todos têm direito a todas as coisas, então o estado de natureza é de extrema insegurança para todos os homens. Dessa forma, o que temos é um estado de guerra e disputa constante, cuja paz só poderia ser instaurada através de um poder acima dos homens. Enquanto isso não for feito, o estado de natureza levará a disputa entre os homens e a discórdia, sendo esta de três tipos:

(i) competição - por lucro

(ii) desconfiança - para manter a própria segurança

(iii) glória - pela reputação

Os homens, sem um poder comum capaz de mantê-los em temor respeitoso e fazê-los obedecer às leis naturais impostas pela razão, estão em estado de guerra de todos contra todos (Lev., p. 109), pois nenhuma lei pode ser feita antes de se ter concordado quanto à pessoa que deverá fazê-la.

Para compreender o fundamento da guerra civil, Hobbes elabora uma antropologia individualista, correspondente a uma humanidade cujos vínculos sociais, políticos e religiosos tornaramse problemáticos. Os conceitos básicos desta antropologia são appetitus et fuga [desejo e fuga] ou desire and fear [desejo e medo], que, apreciados historicamente, formam os elementos de uma teoria da guerra civil. Mas, visto como um todo, o sistema de Hobbes se constrói de tal forma que o resultado — isto é, o Estado - já está contido nas premissas da guerra civil. Os indivíduos são descritos de antemão em função de suas existências como sujeitos, isto é, como súditos do soberano. Sem uma instância estamental intermediária, são integrados à ordem pública de modo a poderem desenvolver-se livremente como indivíduos. O individualismo de Hobbes é o pressuposto de um Estado ordenado e, ao mesmo tempo, a condição de um livre desenvolvimento do indivíduo (KOSELLECK, 1999, p. 26-27).

O estado de natureza se caracteriza pelas paixões dos homens chamadas de direito natural e a razão é a que determina a lei natural. De acordo com a definição de Hobbes, direito natural é a liberdade que cada homem possui de usar o seu próprio poder, da maneira que quiser, para a preservação da sua própria natureza, ou seja, da sua vida; já a lei natural é um preceito ou regra geral, estabelecida pela razão, mediante o qual se proíbe a um homem fazer tudo o que possa destruir a sua própria vida ou privá-la dos meios necessários para a preservar, ou omitir aquilo que se pense melhor contribuir para a preservar (Lev., p. 112). Dessa maneira a melhor maneira de se preservar a vida é buscando-se a paz. A paixão que faz o homem tender para a paz é o medo da morte e a razão irá conduzi-lo a preservar a sua própria vida. No entanto, se certo e errado não têm lugar na condição natural, como Hobbes explica no capítulo XIII, então as leis da natureza, que ele concebe como requerimentos da moralidade, não poderiam ser aplicadas fora do Estado. O Estado é o mais perfeito artifício criado pelo homem e representa a união de todos os homens juntos. Sua criação, apesar de não ser natural, se faz por analogia à natureza. Enquanto os homens possuem corpos físicos dados pela natureza, o Estado é um corpo político criado a partir da arte humana (Lev., p. 112). Faz-se a necessidade de se determinar os meios para a constituição da sociedade civil.

Os fundamentos, para a construção do corpo político, se dão através de um pacto de todos os homens com todos os homens para a formação de um terceiro, isto é, o soberano. O pacto não é feito entre o povo e o soberano, pois as pessoas não possuem nenhuma unidade para serem chamadas de 'povo' antes da existência da sociedade, assim como, o soberano só passa a existir depois do pacto. O soberano, portanto, não faz parte do pacto, pois foi formado a 
partir deste, e, devido a isso, não tem de responder pelo pacto que foi formado. O soberano é a representação do corpo político e o seu poder é chamado de poder soberano e este consiste no poder e na força que cada um dos membros lhe transferiu por meio do pacto ${ }^{4}$. $\mathrm{O}$ poder soberano tem três principais características:

(i) ele é irrevogável, ou seja, não pode ser revogado por nenhum dos contratantes, pois uma vez que todos cederam seus direitos ao soberano, somente ele teria o poder para destituir o corpo político.

(ii) ele é ilimitado, pois o poder soberano é o maior poder que os homens podem atribuir a outros homens. O poder é absoluto porque se outro poder o limitasse, o soberano seria o poder limitador e não o limitado.

(iii) ele é indivisível, pois a divisão do poder soberano seria uma maneira de limitá-lo.

As leis civis baseiam-se nas leis naturais, leis estas que conduziriam ao pacto instaurador do Estado como poder soberano. A justiça como um requerimento moral busca moral da paz. A justiça, portanto, é um requerimento moral porque transferência de direitos é um meio de fazer a paz, direitos são transferidos através de contratos, e a justiça é um meio de manter os contratos. É preciso entender que a teoria hobbesiana se fundamenta nos contratos estabelecidos entre os homens e, por isso, a manutenção dos contratos através da justiça é tão importante para manter o funcionamento do Estado.

Em Hobbes o contrato que instituiu o Estado permite que os males do estado de guerra instaurado pelo estado de natureza sejam instintos através da formação de um poder comum que cause a todos um temor que leve a obediência e a paz promovendo, dessa maneira, a saúde e a segurança do corpo político, assim como a garantia de vida dos corpos naturais. O princípio pelo qual ele parte para a formação do contrato supõe um problema de natureza humana. Tal natureza seria ávida por bens, o que levaria os homens a uma constante disputa entre eles. No entanto, as consequências do contrato são distintas, já que Hobbes pretende conceber as bases formais para a construção do Estado como uma entidade acima de todos os homens sem se preocupar com o tipo de governante que vá gerenciar esse Estado, pois, seja qual for o governante, a sua função permanece a mesma em evitar o estado de guerra e na manutenção da ordem. O que, talvez, crie um tipo de paradoxo, pois aquele que controla o nómos para regular a phýsis é aquele que pode agir livremente segundo seu desejo ${ }^{5}$. No entanto, para Hobbes, não há distinção qualitativa entre os soberanos. Eles cumprem a função de gerenciar o Estado e manter a paz entre os homens e, por isso, "o nome de tirania não significa nem mais nem menos do que o nome de soberania, esteja ela em um ou em muitos homens" (Lev., p. 586).

Dessa forma, Hobbes constrói uma teoria sobre o Estado em que este detém o poder sobre todos os homens que compõem o corpo político. O Estado é o detentor das leis e as promulga para manter o mesmo contrato que o instituiu. Isso faz com as vidas dos indivíduos que ali convivem pertençam indiretamente ao Estado, pois para garantir a paz o Estado também se dá o direito de usar da violência física, o que significa usar de todos os meios que forem necessário para se garantir a paz, inclusive matar aqueles que causem algum distúrbio ao Estado.

\footnotetext{
${ }^{4}$ HOBBES, T. Os Elementos da Lei Natural e Politica. Tradução de Bruno Simões. São Paulo: Martins Fontes, 2010, XIX.10. As citações desta obra são seguidas de capítulo e parágrafo.

5 Isso pode ser visto se compararmos a leitura de Platão do contrato na República, 358e2-359b5.
} 


\section{FOUCAULT: ESTADO E BIOPODER}

Várias são as obras de Foucault que abordam a questão do biopoder e da biopolítica. Entretanto, o ponto que nos diz respeito neste trabalho se refere a estatização da vida biologicamente considerada, isto é, do momento em que o Estado passa a se ocupar do homem enquanto ser vivente. $\mathrm{O}$ que nos leva diretamente à relação que pretendemos estabelecer com a obra Hobbes e o estatuto do poder soberano.

Desse modo, Foucault está interessado em entender a racionalização da violência contra o mito que diz ser a violência irracional. $\mathrm{O}$ Estado se constitui justamente na fórmula moderna que prevê o uso racional da violência como instrumento de controle social. Isso pode ser visto em obras como Vigiar e Punir, Microfísica do Poder, o capítulo final de $A$ vontade de saber ou ainda na série de entrevistas encontradas em Elpoder, una bestia magnífica, só para dar alguns exemplos. Foucault sempre esteve interessado em estudar o poder e de que maneira ele se respalda, entendendo que o poder não se reduz ao conceito de soberano, mas também se encontra nas pequenas instâncias de atuação. Como o próprio Foucault nos diz em uma entrevista: "o que me preocupa são essas relações verdade/poder, saber/poder" (2012, p. 74-75). Ou seja, o poder é aquele que circunda as principais instâncias da vida humana; ter a verdade é ter poder, ter o saber é ter poder, ter razão é ter poder... é no poder que se fundamentos todas as relações sociais. "Estas técnicas de dominação são de uma racionalidade extrema" (FOUCAULT, 2012, p. 60).

O poder soberano tem o intuito de tudo controlar, agindo por toda a parte, de maneira em que se possa consagra o controle estatal sobre todos cidadãos. Isso é um gerenciamento racional do poder para que o poder estatal possa permanecer gerenciando as pessoas mesmo na ausência de um governante de um governante físico, pois existe uma estrutura bem elaborada que possibilita isso. Em Vigiar e Punir, Foucault nos diz que

[a] prisão não pode deixar de fabricar delinquentes. Fabrica-os pelo tipo de existência que faz os detentos levarem: que fiquem isolados nas celas, ou que lhes seja imposto um trabalho inútil, para o qual não encontrarão utilidade, é de qualquer maneira não "pensar no homem em sociedade; é criar uma existência contra a natureza inútil e perigosa"; queremos que a prisão eduque os detentos, mas um sistema de educação que se dirige ao homem pode ter razoavelmente como objetivo agir contra o desejo da natureza? A prisão fabrica também delinquentes impondo aos detentos limitações violentas; ela se destina a aplicar as leis, e a ensinar o respeito por elas; ora, todo o seu funcionamento se desenrola no sentido do abuso de poder (1987, p. 293-294),

O sistema legal utilizado pelo Estado para estabelecer a sua ordem sobre àqueles que vivem dentro dele é uma arbitrariedade que fere os direitos dos indivíduos. Em um sistema prisional isso pode ser observado com maior precisão. O preso, ao mesmo tempo em que pertence ao Estado, é considerado marginal ao Estado, de modo que o controle que se exerce sobre ele é um controle sobre a sua vida também. O Estado, portanto, existe para além da instituição que o constitui, mas também nos pequenos poderes em que sua manifestação é menos visível. É no invisível que o controle do Estado se dá por completo numa espécie de coerção invisível e totalitária.

A vocação do Estado é ser totalitário, quer dizer, ter em definitivo um controle exaustivo do todo. Mas me parece, de todas as formas, que um Estado totalitário em sentido estrito é um 
Estado no qual os partidos políticos, os aparatos do Estado, os sistemas institucionais, a ideologia, se confundem em uma espécie de unidade que se controla de cima a baixo, sem fissuras, sem lacunas e sem desvios possíveis.

É a superposição de todos os aparatos de controle em uma só pirâmide, e o monolitismo das ideologias, os discursos e os comportamentos.

As sociedades de segurança que estão em processo de formação toleram, por sua parte, toda uma série de comportamentos diferentes, variados, em última instância desviados e até antagônicos entre si; com a condição, é certo, de que se inscrevam dentro de certo marco que elimine casas, pessoas e comportamentos considerados como acidentais e perigosos. Esta delimitação “acidente perigoso" corresponde efetivamente ao poder (FOUCAULT, 2012, p. 51).

O que Foucault aqui esclarece é a maneira como o Estado vai consolidando a sua ação para o englobamento do todo. Por mais que façamos a distinção entre sociedades liberais e sociedades fechadas, Estados livres e Estados totalitários, o Estado em si, como instituição forte e consagrada, tende para o totalitarismo. Ou seja, não só pelo âmbito do legal que o Estado atua, mas também pela ideologia, pela prática diária de ações que possibilitem a sua entrada em todas as instâncias sociais. Desse modo, o poder se faz por toda a parte e o controle é total. Se observarmos bem o que Foucault nos diz aqui, poderemos perceber a proximidade com o que Hobbes nos sugere no Leviathan, isto é, a manifestação de um poder maior do que todos os homens juntos e que possa controlá-los para que, tementes ao poder soberano, obedeçam ao Estado e a determinação de suas leis. Somente assim os homens podem sair da condição natural em que se encontram da guerra de todos contra todos para adentrar as leis da razão que são respaldadas no poder do Estado. Sobre a formação do Soberano, Foucault irá indagar:

Seria o caso de concebê-lo, com Hobbes, como a transposição para o príncipe do direito que todos possuiriam, no estado de natureza, de defender sua própria vida à custa da morte dos outros? Ou deve-se ver nele um direito específico que aparece com a formação deste ser jurídico novo que é o soberano? De qualquer modo, o direito de vida e morte, sob esta forma moderna, relativa e limitada, como também sob sua forma antiga e absoluta, é um direito assimétrico. $\mathrm{O}$ soberano só exerce, no caso, seu direito sobre a vida, exercendo seu direito de matar ou contendo-o; só marca seu poder sobre a vida pela morte que tem condições de exigir. O direito que é formulado como "de vida e morte" é, de fato, o direito de causar a morte ou de deixar viver. Afinal de contas, era simbolizado pelo gládio. E talvez se devesse relacionar essa figura jurídica a um tipo histórico de sociedade em que o poder se exercia essencialmente como instância de confisco, mecanismo de subtração, direito de se apropriar de uma parte das riquezas: extorsão de produtos, de bens, de serviços, de trabalho e de sangue imposta aos súditos. O poder era, antes de tudo, nesse tipo de sociedade, direito de apreensão das coisas, do tempo, dos corpos e, finalmente, da vida; culminava com o privilégio de se apoderar da vida para suprimi-la (FOUCAULT, 1999b, p. 128).

O Estado moderno é conceitualmente o retrato do controle sobre a vida humana em todas as instâncias. O direito a vida só existe enquanto em concordância com o Estado, pois perante o contrato, os homens cedem todos os seus direitos ao soberano para que ele lhes preserve a vida, no entanto, a vida pode ser retirada se o soberano assim determinar. "O homem, durante milênios, permaneceu o que era para Aristóteles: um animal vivo e, além disso, capaz de existência política; o homem moderno é um animal, em cuja política, sua vida de ser vivo está em questão" (FOUCAULT, 1999b, p. 134). Como os corpos naturais passam a integrar ao corpo 
político, isso significa dizer que suas vidas fazem parte do Estado, sendo esse o detentor máximo entre a vida e a morte. Isso entra em relação direta como o que Hobbes trata no Leviathan, o que faz com que Foucault se manifeste contrariamente a tal pensamento.

Que Foucault pega Hobbes como seu oponente conceitual e político através de suas perguntas sobre a natureza do poder nas sociedades modernas torna-se aparente em muitos de seus escritos. Em Vigiar e Punir, Foucault usou o Leviathan de Hobbes como pano de fundo no qual ele esboçou sua anatomia alternativa de corpo político. Embora não se refira a Hobbes diretamente, Foucault menciona a teoria do contrato e seu modelo de sociedade em várias ocasiões a fim de defini-lo contra sua própria teoria de sociedade disciplinar (SPIEKER, 2011, p. 191).

Quando Foucault está a tratar da biopolítica, ele está falando de Hobbes e seu Estado Leviathan, pois, mesmo quando não o cita diretamente, Hobbes aparece como autoridade que contrasta com a teoria de Foucault. Desse modo, Foucault procura caracterizar o que Hobbes teria expresso em suas obras para depois ir contra a sua ideia totalitária do Estado. O olhar de Foucault para o Estado moderno não só é descritivo, demonstrando a sua formação, conceituação e abrangência, como também crítico, pois, ao descrever o modus operandi do Estado, Foucault estaria tecendo a sua crítica ao Estado que tudo quer controlar nos indivíduos, fazendo, assim, um controle político, social e cultural de todos os que vivem sobre o seu poder.

A sociedade contemporânea acaba por se utilizar de outros meios para expandir os meios de controle social. A associação entre Estado e tecnologia é uma das maneiras características para se fazer um domínio invisível das pessoas através dos recursos tecnológicos existentes, como jornais eletrônicos, redes sociais e programas de computador. Isso indica que os avanços tecnológicos da época contemporânea criam um tipo de poder que não pode facilmente ser identificado e contribui para o controle estatal dos indivíduos dentro da sociedade. É o que Foucault caracterizou como sociedade disciplinar, construída em cima de punição, vigilância e normas estatais sobre os indivíduos. Dessa forma, as tecnologias que poderiam ser recursos para propagar as liberdades individuais, acabam por se tornar um meio de expansão de controle do Estado.

\section{CONCLUSÃO}

O biopoder se caracteriza pela estatização da vida biologicamente considerada, ou seja, pelo controle do Estado nas várias instâncias da vida humana em sociedade. A concepção moderna de Estado possibilitou a consagração do controle exercido, principalmente através da concepção hobbesiana de Estado. Hobbes através do conceito de poder soberano irá totalizar o poder nas mãos do corpo político, idealizando uma unidade do poder. O Estado é fruto desse poder, que terá sua gênese na paixão do medo da morte violenta, existente em todos os homens.

Foucault irá demonstrar em suas obras que o poder não se faz de forma única, mas ele tem várias instâncias no qual se manifesta, de modo que a própria tendência do Estado de ser totalitário necessita de instanciações de poder para que possa ter e ou manter o controle sobre os corpos vivos existentes dentro da sociedade. Será o poder da soberania, oriundo do referido contrato e da sujeição dos homens a esse poder, que Foucault irá criticar através de seu conceito de biopoder. Dessa maneira, Foucault desnuda a teoria de Hobbes e a sua ideologia de Estado.

O que fizemos nesse trabalho foi apresentar as teorias dos autores supracitados e depois

PRACS: Revista Eletrônica de Humanidades do Curso de Ciências Sociais da UNIFAP https://periodicos.unifap.br/index.php/pracs ISSN 1984-4352 Macapá, v. 12, n. 1, p. 175-182, jan./jun. 2019 
contrapor seus pontos de vista de maneira que pudéssemos ter um paralelo sobre o modo pelo qual o Estado moderno foi concebido em sua gênese através do controle e da punição, mostrando a progressão do seu poder sobre a vida de seus cidadãos.

\section{REFERÊNCIAS}

ANDERSON, Ben. Affect and biopower: towards a politics of life. Transactions of the Institute of British Geographers, v. 37, n. 1, p. 28-43, 2012.

FOUCAULT, Michel. Vigiar e punir: nascimento da prisão. Tradução Raquel Ramalhete. Petrópolis: Vozes, 1987.

- Microfísica do Poder. Organização, introdução e Revisão Técnica de Roberto Machado. Rio de Janeiro: Edições Graal, 1990.

. A Ordem do Discurso. Tradução Laura Fraga de Almeida Sampaio. São Paulo: Edições Loyola, 1999a.

- História da Sexualidade I: A vontade de saber. Tradução de Maria Thereza da Costa Albuquerque e J. A. Guilhon Albuquerque. Rio de Janeiro: Edições Graal, 1999b.

2008. O Nascimento da Biopolítica. Tradução Eduardo Brandão. São Paulo: Martins Fontes, El poder, una bestia magnifica. Edición al cuidado de Edgardo Castro. Buenos Aires: Siglo Veintiuno Editores, 2012.

GUTHRIE, William Keith Chambers. Os Sofistas. São Paulo: Paulus, 2007.

HOBBES, Thomas. Leviathan, or, Matter, Form, and Power of a Commonwealth Ecclesiastical and Civil. Edited by Nelle Fuller. Chicago: The University of Chicago; Encyclopaedia Britannica, 1952.

De Cive. Elementos Filosóficos a respeito do Cidadão. Petrópolis: Vozes, 1993.

- Leviatã. Organizado por Richard Tuck. Tradução de João Paulo Monteiro e Maria

Beatriz Nizza da Silva. São Paulo: Martins Fontes, 2008.

- Elementos da Lei Natural e Política. Tradução de Bruno Simões. São Paulo: Martins

Fontes, 2010.

HOEKSTRA, Kinch. Hobbes on the Natural Condition of Mankind. In: SPRINGBORG, Patricia. The Cambridge Companion to Hobbes's Leviathan, 2007, p. 109-127.

KOSELLECK, Reinhart. Critica e Crise. Uma contribuição à patogênese do mundo burguês. Tradução de Luciana Villas-Boas Castelo-Branco. Rio de Janeiro: Contraponto; EDUERJ, 1999.

SKINNER, Quentin. As Fundações do Pensamento Político Moderno. Tradução Renato Janine Ribeiro e Laura Teixeira Motta. São Paulo: Companhia das Letras, 1996.

SPIEKER, Jörg. Foucault and Hobbes on Politics, Security, and War. Alternatives: Global, Local, Political, v. 36, n. 3, p. 187-199, 2011.

SPRINGBORG, Patricia. The Cambridge Companion to Hobbes's Leviathan. Cambridge: Cambridge University Press, 2007.

CASTRO, Edgardo. Vocabulário de Foucault. Tradução Ingrid Müller Xavier. Belo Horizonte: Autêntica, 2009. 